\title{
Treatment on active surveillance of small renal masses: Progression vs. preference
}

Douglas Cheung; Jed Frankel; Pavinder Tut; Maria Komisarenko; Lisa Martin; Michael Jewett; Antonio Finelli

Departments of Surgery (Urology) and Surgical Oncology, Princess Margaret Cancer Centre, University Health Network and University of Toronto, Toronto, ON, Canada

Cite as: Cheung D, Frankel J, Tut P, et al. Treatment on active surveillance of small renal masses: Progression vs. preference. Can Urol Assoc J 2021 November 18; Epub ahead of print. http://dx.doi.org/10.5489/cuaj.7451

Published online November 18, 2021

Corresponding author: Dr. Douglas Cheung, Departments of Surgery (Urology) and Surgical Oncology, Princess Margaret Cancer Centre, University Health Network and University of Toronto, Toronto, ON, Canada; doug.c.cheung@gmail.com

$* * *$

\section{Abstract}

Introduction: Active surveillance (AS) of small renal masses (SRM) is increasingly recognized as a safe option. A recent U.S. study found that half of patients receiving treatment on AS were for preference, but these findings may not be generalizable to other jurisdictions and healthcare models. We aimed to investigate AS failure rates and causes among a contemporary biopsyevaluated cohort in Canada.

Methods: A retrospective review was performed of SRM patients on AS undergoing treatment at our tertiary care center (1999-2018). All patients had undergone renal biopsy and been diagnosed with renal cell carcinoma (RCC). Demographic and clinical parameters surrounding the decision to treat were extracted from chart review. Indications for treatment were dichotomized into clinical (radiographical) progression or preference. Qualitative assessment of clinic notes confirmed treatment indication. Ethics approval was obtained.

Results: A total of 38 SRM-RCC patients who underwent treatment on AS were identified, of which 29 had been on AS $\geq 1$ year. Most (75.9\%) were male, and the mean age beginning AS was $65.9 \pm 9.0$ years. Most patients had clear-cell RCC with low-grade disease. Seventeen of 29 (58.6\%) patients experienced clinical progression after $3.82(2.57-7.16)$ years, whereas preference accounted for 12/29 (41.4\%) after 2.22 (1.69-3.53) years (time-to-treatment $\mathrm{p}=0.032$ ). The longest duration on AS was 14.2 years prior to clinical progression. No patients had metastatic progression before treatment. 
Conclusions: Two-fifths of patients received treatment for preference and at a much higher rate vs. clinical progression. These findings suggest a clinical gap where effective patient counselling, prior to and during AS, may improve adherence.

\section{Introduction}

Small renal masses (SRM), defined as incidentally discovered enhancing renal masses less than four centimetres in maximal diameter with imaging consistent with T1aNOM0 renal cell carcinoma (RCC), have become increasingly common due to widespread imaging. ${ }^{1,2}$ Numerous treatment approaches including surgical resection, tissue ablation, and active surveillance (AS) have all been proven to be effective in the management of SRMs..$^{3-5}$ Active surveillance in particular, is gaining increasing recognition as an acceptable and safe option in patients, especially in older and/or comorbid individuals. ${ }^{6-8}$

Of patients placed on AS, whom are serially monitored through radiographic and clinical follow-up, approximately $1 / 3$ of patients progress to delayed treatment in a recent systematic review by Gupta et al. ${ }^{9}$ Of these, half did so for radiographic progression, including large overall size or rapid growth rate (clinically appropriate), and half (51.9\%) were shown to be due to patient or physician preference in the absence of disease progression (potentially preventable/modifiable). Similarly, the Delayed Intervention and Surveillance for Small Renal Masses (DISSRM) registry published last year demonstrated concordant results: 22/46 (47.8\%) patients undergoing delayed treatment were for patient preference. ${ }^{10}$

However, many of the patients included in these studies do not have biopsy histology readily available; and their findings may not be generalizable to other jurisdictions and healthcare models with different practice patterns, counselling, and treatment indications. We aimed to investigate AS failure rates and causes amongst a contemporary biopsy-evaluated cohort in Canada.

\section{Methods}

A retrospective review was performed of SRM-RCC patients on AS undergoing treatment at our tertiary care centre over 20 years (1999-2015 with follow-up to 2018). This cohort of AS patients has been previously published as part of the Renal Cell Carcinoma Consortium of Canada (RC4) phase-II AS trial ${ }^{11}$ and Princess Margaret Cancer Centre (PMCC) AS cohort ${ }^{12}$, and represent the subset of patients belonging to our centre (PMCC). Our centre has 6 urologic-oncologists and has excellent access to interventional radiology, including routine renal rounds. In brief, all patients within this cohort had undergone percutaneous renal mass biopsy (RMB) and have been diagnosed with RCC, excluding those with benign or non-diagnostic biopsies.

Demographic, clinical, and tumor characteristics (including age at AS enrollment, gender, initial tumor size, and biopsy histology and grade) were extracted from chart review 
surrounding the decision to treat their SRM. For our primary outcome, indications for treatment were dichotomized as either for clinical (radiographic) progression or preference (e.g. anxiety). Progression was defined as SRM growth $>0.5 \mathrm{~cm} /$ year for 2 years, absolute size $>4 \mathrm{~cm}$, or volume doubling <1 year, and was assessed in the time (up to 2 years dependent on criteria) immediately preceding treatment. Qualitative assessment of clinic notes confirmed treatment indication in all patients. Additionally, treatment outcomes including treatment type (nephrectomy or renal frequency ablation [RFA]), time to treatment, and final histology and grade (if surgically managed) were recorded. Patients who remained on AS $<1$ year prior to treatment were included in sensitivity analyses only, as these patients represented a heterogenous group of very fast progressors and those not truly interested in AS. Once patients reached progression criterion thresholds, it was standard practice to recommend treatment; however, the individual counselling, informed discussions, and decisions for AS, managing anxiety, and treatment were at the discretion of the patient and treating physician.

Descriptive statistics were completed on all variables using Student's t-test, Wilcoxon rank-sum test, chi-square test, or Fisher's exact test as appropriate for continuous and categorical data. Treatment survival distributions by indication (clinical progression or preference) were descriptively plotted using the Kaplan-Meier product-limit method. These were intended for graphical representation only, and no comparative testing was completed (as treatment indications signify outcome measures, not exposures). A p-value $<0.05$ was used to indicate statistical significance for two-tailed comparison. All analyses were completed using SAS Statistical Software. Ethics approval was obtained after institutional review.

\section{Results}

A total of 163 SRM-RCC patients on active surveillance were identified, of which 44 underwent treatment while on AS. After excluding patients with concurrent multiple tumors, incomplete biopsy or imaging results, or lost to follow-up, 38 patients with SRM-RCC on AS and 29 on AS for $\geq 1$ year were included (Figure 1). All patients underwent treatment with either nephrectomy or RFA during follow-up, and had biopsy-proven malignant histology.

Demographic and clinical variables are available in Table 1.22 male (75.9\%) and 7 (24.1\%) female patients were identified with a mean age at AS initiation of $65.9 \pm 9.0$ years. The youngest patient was 46.7 years old and the oldest patient was 83.0 years old. The majority of patients had clear cell RCC pathology on biopsy (72.4\%) with low grade (Grade 1-2; 95.8\%) disease. The average tumor size at presentation was $2.50 \pm 0.63 \mathrm{~cm}$.

Of 29 treated patients, 18 (62.1\%) elected for nephrectomy ( 5 radical nephrectomy, 13 partial nephrectomy) and 11 (37.9\%) for RFA. Using progression criteria, 17/29 (58.6\%) of patients experienced clinical progression versus $12 / 29$ patients (41.4\%) undergoing treatment for preference (Table 2). Patients with progression frequently met multiple criteria of absolute size $(13 / 17,76.5 \%)$, growth rate $(12 / 17,70.6 \%)$, and volume doubling $(8 / 17,47.1 \%)$, respectively. The time to treatment was significantly shorter for patients being treated for preference versus 
clinical progression: $2.22(1.69-3.53)$ years versus $3.82(2.57-7.16)$ years, respectively $(\mathrm{p}=0.032)$. The longest duration that a patient was on AS was 14.2 years prior to clinical progression. The time to treatment for patients progressing for either clinical progression or preference is graphically depicted in Figure 2. There were no significant differences in final surgical histology or grade between groups. All patients treated with nephrectomy for preference had pT1a lesions, whereas 5 patients with progression were pT1b (41.7\%) and 2 were pT3b $(16.7 \%)$. No patients had metastatic progression prior to treatment; one patient following radical nephrectomy developed recurrence to the renal bed and subsequent metastatic disease.

Qualitative chart review demonstrated agreement in 27/29 (93\%) cases with one patient crossing over each category (one met progression criteria but deferred treatment until worsening clinical anxiety, and one had a single measurement of rapid growth but did not meet criteria). Results were similar when patients on surveillance $<1$ year were included (17/38, 44.7\% treatment for preference).

\section{Discussion}

In this study, we queried our institutional database of SRM patients on AS in Toronto, Canada. Despite being biopsy (histology)-informed, we found that the indications for AS failure appeared to be similar to those recently reported in American cohort studies ${ }^{10}$, with almost $40-50 \%$ of patients choosing to progress onto treatment despite clinical stability. Furthermore, despite having similar characteristics as those who ultimately clinically progressed, the time to treatment for patients being treated for preference was almost half of that for progression. This alone was a surprising finding amongst a contemporary, biopsy-informed, Canadian cohort, and warrants further investigation.

There are multiple potential explanations for this relatively-high proportion of preference-driven treatment, both amongst Americans and Canadians. Uncertainties about the disease and safety of AS may be important drivers of patient and clinician anxiety. ${ }^{10,13}$ Indeed, while metastases remain rare in SRM patients on AS, sporadic cases of rapid clinical progression illustrate our incomplete understanding of the disease biology and natural history beyond histology. ${ }^{14}$ In this study, we elected to focus our investigation on patients with $>1$ year on AS (precluding some of the very-fast progressors). However, analyses with and without these patients demonstrated consistent findings with a high proportion of patients being treated for preference regardless, suggesting that other factors may have an important role. Along these lines, another reason may represent individual uncertainty about their own overall health: patients (and their clinicians) may be hesitant to delay treatment if they worry that they will not be as fit for intervention at a later date. Ultimately, the relationship between patient/clinician anxiety and treatment is likely to be complex, with numerous inter-related and confounding elements; a conceptual Directed Acyclic Graph (DAG) for the causal relationship between patient/clinician anxiety and treatment is included in Supplemental Figure 1. 
The psycho-oncological effects and stigma around cancer should also be considered. One important difference between surgery and AS is the notion that the patient still "has cancer" when they are on AS, as opposed and being "cancer-free" after surgery or ablation. There is a wealth of literature demonstrating that following diagnosis, patients' quality of life declines, even when asymptomatic. ${ }^{15,16}$ In particular, a cancer diagnosis and illness uncertainty was found to predict general- and cancer-specific quality of life, intrusive thoughts, and avoidance behaviours in a study of SRM patients by Matin et al. ${ }^{15}$ Similarly from the treating physician's perspective, taking action may also be seen as preferable to surveillance (i.e. commission bias), and can be accentuated based on previous (negative) experiences with surveillance approaches in other circumstances (i.e. recall bias). These effects on care provision appear to extend medicolegally as well: the most common reason for over-treatment in the US is fear of malpractice according to a nationwide study. ${ }^{17}$ In the case of SRMs, surgery also remains the standard-ofcare in many guideline statements. ${ }^{7,18}$

Finally, it is worthwhile to consider the role of RMB, both as it pertains to the diagnostic uncertainty of RMB and whether RMB itself contributes to patient anxiety. There remains much controversy about the use of biopsy, and whether they are representative of the true pathophysiology in each patient: false negatives, false positives, and tumor heterogeneity are all important issues, in addition to a $14 \%$ non-diagnostic rate with RMB. ${ }^{13,19}$ Because of this diagnostic uncertainty, both physicians and patients alike may err on the side of caution, that being extirpative surgery or tissue ablation, even after RMB. Further research is needed to improve the diagnostic certainty of RMBs and other genetic or histologic biomarkers to reassure patients of their risk of disease progression when opting for AS. A second criticism is RMBassociated anxiety: in a recent study by Goldberg et al., patients with a malignant biopsy were found to have the highest psychological distress in those selecting active surveillance versus treatment. ${ }^{20}$ Intuitively, these match the findings of our cohort, explaining the high incidence of non-progression-driven treatment in SRM-RCC patients. Notably however, their psychological distress regression estimates contrasted with those of RMB or surveillance individually (nonsignificant to borderline significant) suggesting that this effect is not driven by the performance of biopsy alone or AS itself, rather by how patients respond to AS for a malignant diagnosis. ${ }^{20}$ This context underscores the aforementioned psycho-oncological effects and stigma surrounding cancer (despite excellent RCC-specific survival), and thus, the imperative for improved patient counselling.

Moving forward, learning from an analogous example in Urology, patients on AS for prostate cancer are subject to similar long-term surveillance with clinical and biochemical follow-up and relatively low metastatic risk. ${ }^{21}$ In contrast however, very few (5-10\%) prostate cancer patients progress onto treatment for preference without clinical indication and comfort with this modality has increased with time. ${ }^{22,23}$ This insight provides a valuable opportunity to learn beyond the SRM literature: in one study measuring anxiety and distress for AS prostate cancer patients, the larger the role that the physician played in the treatment decision, the more 
doubts the patient had regarding their own treatment. ${ }^{24}$ Furthermore, standardized counselling addressing patient- and physician-level biases has been shown to increase acceptance of AS treatment modalities for prostate cancer. ${ }^{25}$ Incorporation of these shared decision-making strategies, training, and standardization should be a focus for SRMs as well. Decision aids for the management of small renal masses ${ }^{26}$ are further examples of advances to the provision of standardized and evidence-based information to aid patients and their caregivers in the decisionmaking process to address these biases.

\section{Limitations}

Our study was limited by its small sample size, precluding further analysis of the predictors of non-clinically indicated AS failure. However, these features would likely need to be evaluated in a prospective setting along with patient interviews to garner a better understanding as no clear demographic differences were evident, and our study is hypothesis-generating in this respect. Furthermore, despite the limited number of total patients, this still represents one of the largest studies of the indications for delayed intervention which account for a minor proportion of patients on AS, and of which only a fraction are biopsy-evaluated. This is further strengthened by the chart review confirming the treatment intent and indication in our cohort, and long duration of follow-up.

\section{Conclusions}

In our retrospective series, two-fifths of patients elected to transition to treatment for preference, and at much higher rate versus clinical progression for growth or absolute tumour size. Although the causes are likely multi-factorial representing patient, disease, physician, and psycho-oncological factors, these findings point to a clinical gap where effective patient counselling, prior to and during AS, may improve adherence. 


\section{References}

1. Volpe, A. The role of active surveillance of small renal masses. International journal of surgery 2016;36:518-24. http://www.ncbi.nlm.nih.gov/pubmed/27321381

2. Kane, C. J., K. Mallin, J. Ritchey, et al. Renal cell cancer stage migration: analysis of the National Cancer Data Base. Cancer 2008;113:78-83. http://www.ncbi.nlm.nih.gov/pubmed/18491376

3. Withington, J., J. B. Neves and R. Barod. Surgical and Minimally Invasive Therapies for the Management of the Small Renal Mass. Current urology reports 2017;18:61. http://www.ncbi.nlm.nih.gov/pubmed/28664237

4. Smaldone, M. C., A. Kutikov, B. L. Egleston, et al. Small renal masses progressing to metastases under active surveillance: a systematic review and pooled analysis. Cancer 2012;118:997-1006. http://www.ncbi.nlm.nih.gov/pubmed/21766302

5. Kunkle, D. A., B. L. Egleston and R. G. Uzzo. Excise, ablate or observe: the small renal mass dilemma--a meta-analysis and review. The Journal of urology 2008;179:1227-33; discussion 33-4. http://www.ncbi.nlm.nih.gov/pubmed/18280512

6. Finelli, A., N. Ismaila, B. Bro, et al. Management of Small Renal Masses: American Society of Clinical Oncology Clinical Practice Guideline. Journal of clinical oncology : official journal of the American Society of Clinical Oncology 2017;35:668-80. http://www.ncbi.nlm.nih.gov/pubmed/28095147

7. Jewett, M. A., R. Rendon, L. Lacombe, et al. Canadian guidelines for the management of small renal masses (SRM). Canadian Urological Association journal = Journal de l'Association des urologues du Canada 2015;9:160-3. http://www.ncbi.nlm.nih.gov/pubmed/26225162

8. Cheung, D. C. and A. Finelli. Active Surveillance in Small Renal Masses in the Elderly: A Literature Review. European urology focus 2017;3:340-51. http://www.ncbi.nlm.nih.gov/pubmed/29175368

9. Gupta, M., M. L. Blute, Jr., L. M. Su, et al. Delayed Intervention of Small Renal Masses on Active Surveillance. Journal of kidney cancer and VHL 2017;4:24-30. http://www.ncbi.nlm.nih.gov/pubmed/28725541

10. Gupta, M., R. Alam, H. D. Patel, et al. Use of delayed intervention for small renal masses initially managed with active surveillance. Urologic oncology 2019;37:18-25. http://www.ncbi.nlm.nih.gov/pubmed/30446459

11. Jewett, M. A., K. Mattar, J. Basiuk, et al. Active surveillance of small renal masses: progression patterns of early stage kidney cancer. European urology 2011;60:39-44. http://www.ncbi.nlm.nih.gov/pubmed/21477920

12. Finelli, A., D. C. Cheung, A. Al-Matar, et al. Small Renal Mass Surveillance: Histologyspecific Growth Rates in a Biopsy-characterized Cohort. European urology 2020;78:4607. http://www.ncbi.nlm.nih.gov/pubmed/32680677

13. Golan, S., P. Lotan, S. Tapiero, et al. Diagnostic Needle Biopsies in Renal Masses: Patient and Physician Perspectives. European urology focus 2018;4:749-53. http://www.ncbi.nlm.nih.gov/pubmed/28753807 
14. Gill, I. S., M. Aron, D. A. Gervais, et al. Clinical practice. Small renal mass. The New England journal of medicine 2010;362:624-34. http://www.ncbi.nlm.nih.gov/pubmed/20164486

15. Parker, P. A., F. Alba, B. Fellman, et al. Illness uncertainty and quality of life of patients with small renal tumors undergoing watchful waiting: a 2-year prospective study. European urology 2013;63:1122-7. http://www.ncbi.nlm.nih.gov/pubmed/23419322

16. Matin, S. F. Kidney cancer: Quality-of-life outcomes in patients with small renal masses. Nature reviews. Urology 2016;13:443-4. http://www.ncbi.nlm.nih.gov/pubmed/27400666

17. Lyu, H., T. Xu, D. Brotman, et al. Overtreatment in the United States. PloS one 2017;12:e0181970. http://www.ncbi.nlm.nih.gov/pubmed/28877170

18. Finelli, A., N. Ismaila and P. Russo. Management of Small Renal Masses: American Society of Clinical Oncology Clinical Practice Guideline Summary. Journal of oncology practice 2017;13:276-8. http://www.ncbi.nlm.nih.gov/pubmed/28118108

19. Patel, H. D., M. H. Johnson, P. M. Pierorazio, et al. Diagnostic Accuracy and Risks of Biopsy in the Diagnosis of a Renal Mass Suspicious for Localized Renal Cell Carcinoma: Systematic Review of the Literature. The Journal of urology 2016;195:1340-7. http://www.ncbi.nlm.nih.gov/pubmed/26901507

20. Goldberg, H., R. Ajaj, J. O. H. Caceres, et al. Psychological distress associated with active surveillance in patients younger than 70 with a small renal mass. Urologic oncology 2020;38:603 e17- e25. http://www.ncbi.nlm.nih.gov/pubmed/32253117

21. Briganti, A., N. Fossati, J. W. F. Catto, et al. Active Surveillance for Low-risk Prostate Cancer: The European Association of Urology Position in 2018. European urology 2018;74:357-68. http://www.ncbi.nlm.nih.gov/pubmed/29937198

22. Venderbos, L. D., R. C. van den Bergh, M. J. Roobol, et al. A longitudinal study on the impact of active surveillance for prostate cancer on anxiety and distress levels. Psychooncology 2015;24:348-54. http://www.ncbi.nlm.nih.gov/pubmed/25138075

23. Marzouk, K., M. Assel, B. Ehdaie, et al. Long-Term Cancer Specific Anxiety in Men Undergoing Active Surveillance of Prostate Cancer: Findings from a Large Prospective Cohort. The Journal of urology 2018;200:1250-5. http://www.ncbi.nlm.nih.gov/pubmed/29886089

24. van den Bergh, R. C., M. L. Essink-Bot, M. J. Roobol, et al. Anxiety and distress during active surveillance for early prostate cancer. Cancer 2009;115:3868-78. http://www.ncbi.nlm.nih.gov/pubmed/19637245

25. Ehdaie, B., M. Assel, N. Benfante, et al. A Systematic Approach to Discussing Active Surveillance with Patients with Low-risk Prostate Cancer. European urology 2017;71:866-71. http://www.ncbi.nlm.nih.gov/pubmed/28129893

26. McAlpine, K., R. H. Breau, D. Stacey, et al. Shared decision-making for the management of small renal masses: Development and acceptability testing of a novel patient decision aid. Canadian Urological Association journal = Journal de l'Association des urologues du Canada 2020;14:385-91. http://www.ncbi.nlm.nih.gov/pubmed/32574143 


\section{Figures and Tables}

Fig. 1. Flow chart of small renal mass (SRM)-renal cell carcinoma (RCC) patients progressing onto treatment. AS: active surveillance.

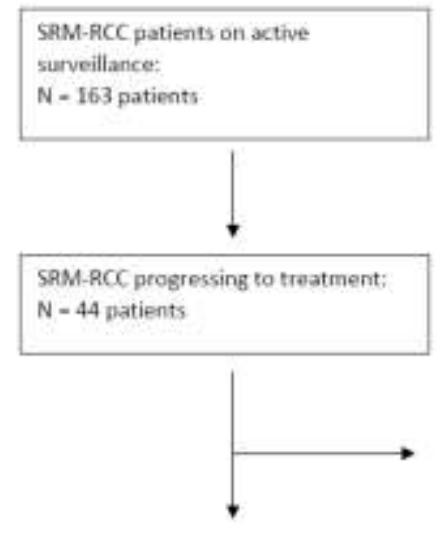

$N=38$ patients considered for analysis
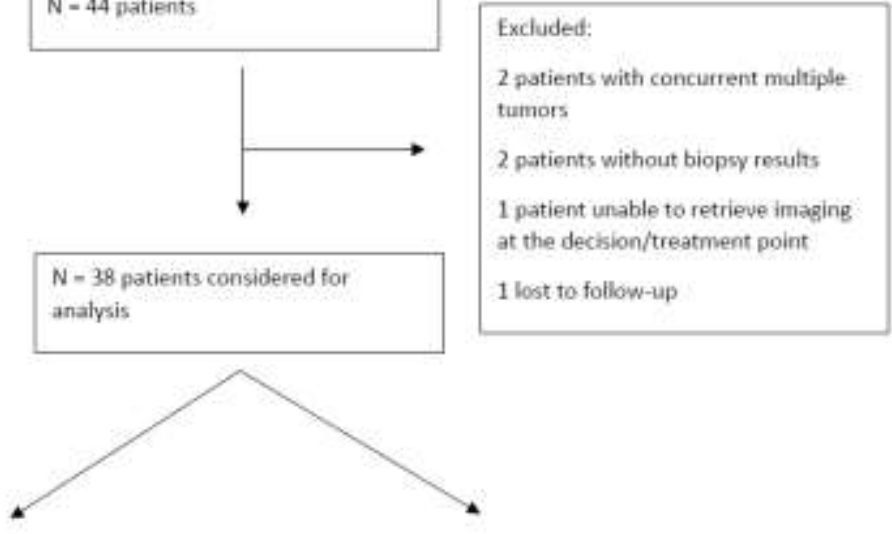

Analyzed Cohort:

$N=29$

Plemoved 8 patients on $A S<1$ year =

heterogenous group of very fast

progressors or patients not interested

in $\mathrm{AS}$; and 1 patient whom imaging.

Was available at treatment/decision

point but not the prior imaging

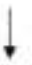

$17 / 29$ progressed (58.66\%)

$12 / 29$ patient preference/aruxiety

(41.4\%)
Sensitivity Analysis:

$N=38$
$21 / 38$ progressed (55.3\%)

$17 / 38$ patient preference/anxiety (44.7\%)

$*$ Progression defined as growth $>0.5 \mathrm{~cm} / \mathrm{yr}$ for 2 years, absolute size $>4 \mathrm{~cm}$, volume doubling < 1 yr 
Fig. 2. Overlaid treatment survival distributions for patients treated secondary to clinical progression and preference. These represent conditional probabilities of patients who ultimately received treatment (for either indication). As treatment indications signify outcome measures (not exposures), no comparative analysis is completed.

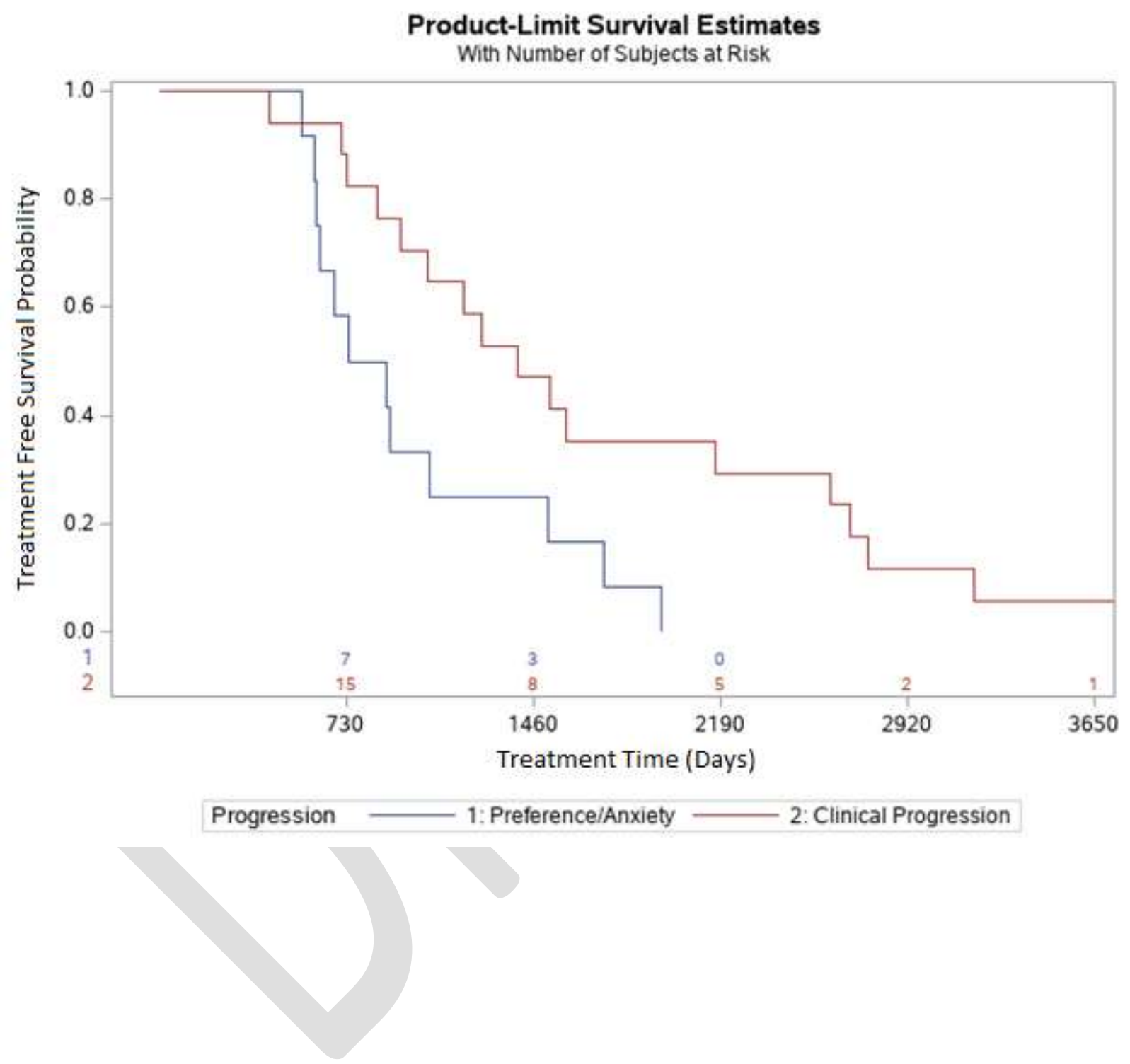




\begin{tabular}{|c|c|c|c|c|}
\hline $\begin{array}{l}\text { Demographic } \\
\text { and clinical } \\
\text { variables }\end{array}$ & $\begin{array}{l}\text { Patients treated for } \\
\text { preference }(n=12)\end{array}$ & $\begin{array}{l}\text { Patients treated } \\
\text { for clinical } \\
\text { progression }(n=17)\end{array}$ & Combined (n=29) & $\begin{array}{c}\text { p for } \\
\text { preference } \\
\text { vs. } \\
\text { progression }\end{array}$ \\
\hline Age $($ mean \pm SD) & $62.6 \pm 9.3$ years & $68.2 \pm 8.3$ years & $65.9 \pm 9.0$ years & 0.10 \\
\hline Sex (\% male) & $8(66.7 \%)$ & $14(82.4 \%)$ & $22(75.9 \%)$ & 0.40 \\
\hline $\begin{array}{l}\text { Initial tumor } \\
\text { presentation size } \\
(\text { mean } \pm \text { SD) }\end{array}$ & $2.38 \pm 0.68 \mathrm{~cm}$ & $2.58 \pm 0.59 \mathrm{~cm}$ & $2.50 \pm 0.63 \mathrm{~cm}$ & 0.41 \\
\hline Biopsy histology & $\begin{aligned}- & 7 \text { clear-cell RCC } \\
& (58.3 \%) \\
- & 1 \text { clear-cell papillary } \\
& \text { RCC }(8.3 \%) \\
- & 1 \text { papillary type } 1 \\
& (8.3 \%) \\
- & 2 \text { papillary type } 2 \\
& (16.7 \%) \\
- & 1 \text { papillary NOS } \\
& (8.3 \%)\end{aligned}$ & $\begin{array}{l}-14 \text { clear-cell } \\
\text { RCC }(82.4 \%) \\
-1 \text { papillary type } 1 \\
\text { (5.9\%) } \\
-1 \text { papillary type } 2 \\
\text { (5.9\%) } \\
-1 \text { mixed } \\
\text { (papillary type } 1, \\
\text { clear cell RCC; } \\
5.9 \%)\end{array}$ & \begin{tabular}{|l}
-21 clear-cell RCC \\
$(72.4 \%)$ \\
-1 clear-cell \\
papillary RCC \\
(3.5\%) \\
-2 papillary type 1 \\
$\quad(6.9 \%)$ \\
-3 papillary type 2 \\
$\quad(10.3 \%)$ \\
-1 mixed \\
(papillary type 1, \\
clear-cell RCC; \\
$3.5 \%)$ \\
-1 papillary NOS \\
(3.5\%)
\end{tabular} & 0.41 \\
\hline $\begin{array}{l}\text { Maximum biopsy } \\
\text { grade }\end{array}$ & $\begin{array}{l}-4 \text { grade } 1(50.0 \%) \\
-3 \text { grade } 2(37.5 \%) \\
-1 \text { grade } 3(12.5 \%) \\
-4 \text { missing }\end{array}$ & $\begin{array}{l}-8 \text { grade } 1 \\
(50.0 \%) \\
-8 \text { grade } 2 \\
(50.0 \%) \\
-1 \text { missing }\end{array}$ & \begin{tabular}{|l|}
-12 grade 1 \\
\\
$\quad(50.0 \%)$ \\
-11 grade 2 \\
$\quad(45.8 \%)$ \\
-1 grade $3(4.2 \%)$ \\
-5 missing \\
\end{tabular} & 0.46 \\
\hline $\begin{array}{l}\text { Reasons for } \\
\text { clinical } \\
\text { progression }\end{array}$ & N/A & $\begin{array}{l}-12 \text { growth }>0.5 \\
\text { cm/year for } 2 \\
\text { years }(70.6 \%) \\
-13 \text { absolute size } \\
>4 \mathrm{~cm}(76.5 \%) \\
-8 \text { volume } \\
\text { doubling }<1 \text { year } \\
(47.1 \%)^{*}\end{array}$ & N/A & N/A \\
\hline
\end{tabular}

"Totals exceed $100 \%$ as patients may meet more than one criterion. NOS: not otherwise specified; RCC: renal cell carcinoma; SD: standard deviation. 


\begin{tabular}{|c|c|c|c|c|}
\hline $\begin{array}{l}\text { Treatment } \\
\text { outcomes }\end{array}$ & $\begin{array}{l}\text { Patients treated for } \\
\text { preference }(n=12)\end{array}$ & $\begin{array}{l}\text { Patients treated for } \\
\text { clinical progression } \\
\qquad(\mathbf{n}=17)\end{array}$ & Combined $(n=29)$ & $\begin{array}{c}\text { p for } \\
\text { preference } \\
\text { vs. } \\
\text { progression }\end{array}$ \\
\hline $\begin{array}{l}\text { Time to } \\
\text { treatment, } \\
\text { median (IQR) }\end{array}$ & $2.22(1.69-3.53)$ years & $3.82(2.57-7.16)$ years & $2.89(2.00-4.75)$ years & 0.032 \\
\hline $\begin{array}{l}\text { Treatment } \\
\text { type }\end{array}$ & $\begin{array}{l}-6 \text { nephrectomy } \\
\quad(50.0 \%) \\
-6 \text { RFA }(50.0 \%)\end{array}$ & $\begin{array}{l}-12 \text { nephrectomy } \\
(70.6 \%) \\
-5 \text { RFA }(29.4 \%)\end{array}$ & $\begin{aligned}- & 18 \text { nephrectomy } \\
& (62.1 \%) \\
- & 11 \text { RFA }(37.9 \%)\end{aligned}$ & 0.44 \\
\hline $\begin{array}{l}\text { Final } \\
\text { nephrectomy } \\
\text { histology }\end{array}$ & $\begin{aligned} &- 3 \text { clear-cell RCC } \\
&(50.0 \%) \\
&- 3 \text { papillary type } 1 \\
&(50.0 \%) \\
&\end{aligned}$ & \begin{tabular}{|l}
-10 clear-cell RCC \\
$(83.3 \%)$ \\
-2 papillary type 1 \\
$(16.7 \%)$ \\
\end{tabular} & $\begin{array}{l}-13 \text { clear-cell RCC } \\
(72.2 \%) \\
-5 \text { papillary type } 1 \\
(27.8 \%) \\
\end{array}$ & 0.27 \\
\hline $\begin{array}{l}\text { Nephrectomy } \\
\text { stage }\end{array}$ & -6 pT1a $(100 \%)$ & $\begin{array}{l}-5 \text { pT1a }(41.7 \%) \\
-5 \text { pT1b }(41.7 \%) \\
-2 \text { pT3b }(16.7 \%) \\
\end{array}$ & $\begin{array}{l}-11 \text { pT1a }(61.1 \%) \\
-5 \text { pT1b }(27.8 \%) \\
-2 \text { pT3b }(11.1 \%) \\
\end{array}$ & 0.07 \\
\hline $\begin{array}{l}\text { Nephrectomy } \\
\text { grade }\end{array}$ & $\begin{array}{l}-2 \text { grade } 1(33.3 \%) \\
-3 \text { grade } 2(50.0 \%) \\
-1 \text { grade } 3(16.7 \%)\end{array}$ & $\begin{array}{l}-2 \text { grade } 1(16.7 \%) \\
-6 \text { grade } 2(50.0 \%) \\
-4 \text { grade } 3(33.3 \%)\end{array}$ & $\begin{array}{l}-4 \text { grade } 1(22.2 \%) \\
-9 \text { grade } 2(50.0 \%) \\
-5 \text { grade } 3(27.8 \%)\end{array}$ & 0.82 \\
\hline
\end{tabular}

IQR: interquartile range; RCC: real cell carcinoma; RFA: renal frequency ablation. 
Supplementary Fig. 1. Potential directed acyclic graph (DAG) for the causal relationship between patient (and clinician) anxiety and the receipt of subsequent treatment in patients undergoing active surveillance for small renal masses (SRM).

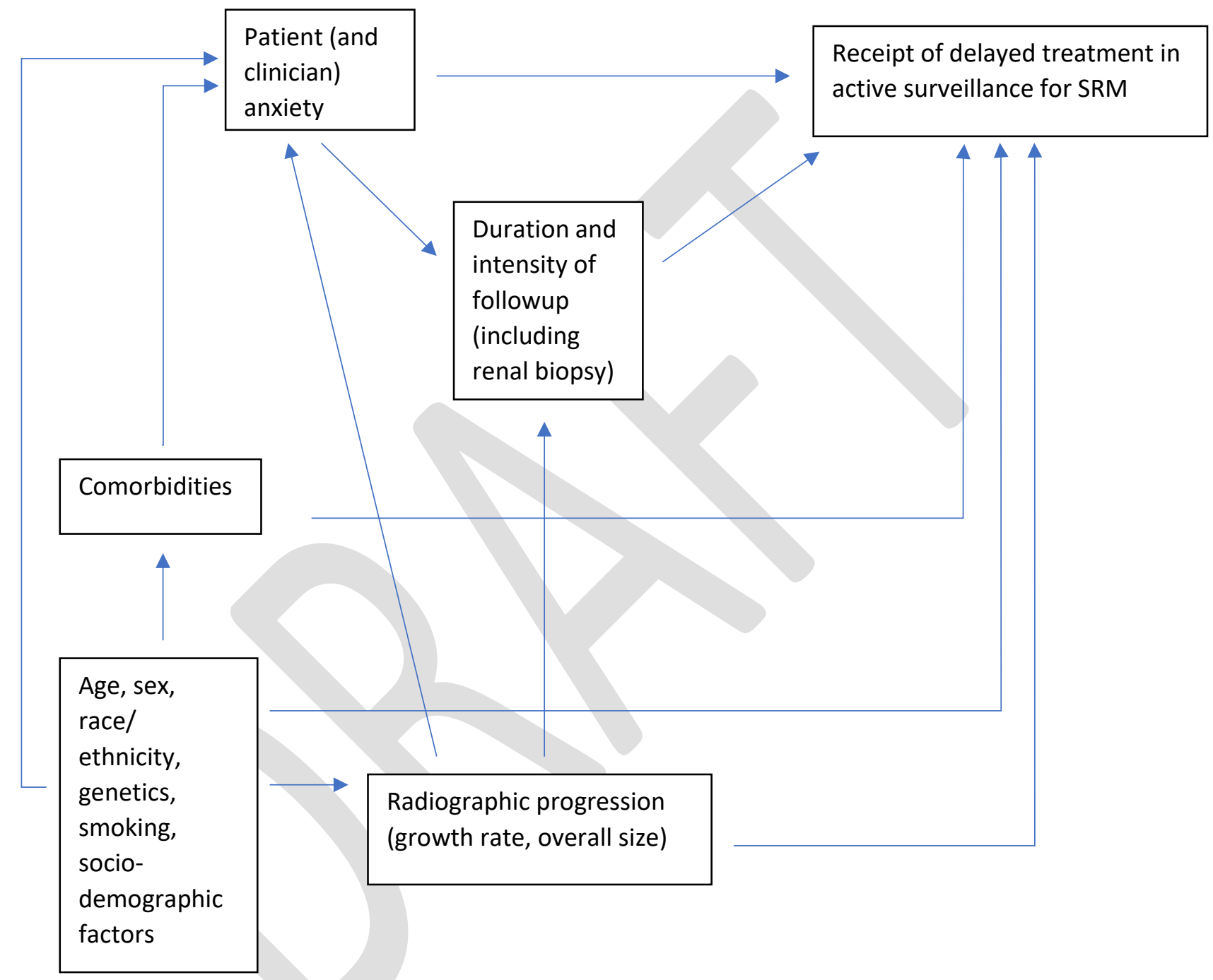

